\title{
Implementation of a $\beta$-Agonist/Airway Clearance Protocol in a Pediatric ICU
}

\author{
Gary R Lowe MEd RRT-NPS RPFT, J Randy Willis MBA RRT-NPS, Shasha Bai PhD, and \\ Mark J Heulitt MD FAARC
}

\begin{abstract}
BACKGROUND: Respiratory therapist (RT)-driven protocols have been in use for over 30 years. Protocols have been reported to decrease unnecessary or harmful therapy, health-care costs, and hospital stay. This study represents the evaluation of an original respiratory care protocol in the pediatric ICU at Arkansas Children's Hospital for $\boldsymbol{\beta}$-agonist and airway clearance interventions where one did not exist. METHODS: This project was composed of 2 parts: a survey administered to RTs and licensed independent practitioners and a retrospective review of outcome data comparing a therapist-driven $\beta$-agonist/airway clearance protocol with physician-directed respiratory care ordering in a patient population admitted for acute respiratory failure. RESULTS: Acceptance of the protocol was evident in the survey responses because overall perceptions surrounding the implementation of the $\beta$-agonist/airway clearance protocol were positive, and responders perceived that the protocol implementation elevated the status and increased the value of respiratory therapists. For the comparison of physician-directed orders with therapist-driven protocols, there were no significant differences between pre- and post-intervention groups for mean age, sex, mean daily acuity, or mean weighted daily acuity $(P=.33, .19,>.99$, and .79 , respectively $)$. There were also no differences in pediatric index of mortality 2, pediatric index of mortality 2 rate of mortality, pediatric risk of mortality 3 probability of death, and pediatric risk of mortality 3 scores $(P=.63$, $.56, .19$, and .44 , respectively) between the 2 groups. When comparing physician-directed orders to therapist-driven protocols, all outcome measures (length of stay, $\beta$-agonist therapies, airway clearance therapies, and ventilator days) showed statistically and clinically important reductions, adjusting for subject characteristics $(P<.001)$ for the therapist-driven protocol group. CONCLUSIONS: In this institution, implementation of a $\beta$-agonist/airway clearance protocol resulted in significant reductions of subject interventions and improved outcomes by decreasing length of stay and ventilator days as well as contributing information where clinical evidence is scant, specifically the pediatric ICU. Key words: respiratory care protocols; therapist-driven protocols; quality improvement; evidence-based medicine. [Respir Care 2017;62(3):259-267. (C) 2017 Daedalus Enterprises]
\end{abstract}

\section{Introduction}

Respiratory care protocol development and utilization were first described in $1981 .{ }^{1}$ This innovative approach to

\footnotetext{
Mr Lowe and Mr Willis are affiliated with Respiratory Care Services, Arkansas Children's Hospital, Little Rock, Arkansas. Dr Bai is affiliated with the Biostatistics Program, Department of Pediatrics, University of Arkansas for Medical Sciences, Little Rock, Arkansas. Dr Heulitt was affiliated with the Critical Care Medicine Section, Department of Pediatrics, College of Medicine, University of Arkansas for Medical Sciences, Little Rock, Arkansas at the time of this study and is currently affiliated with the Spence and Becky Wilson Baptist Children's Hospital, Memphis, Tennessee.
}

respiratory care included patient evaluation, appropriate therapy selection and administration, timely patient reas-

\footnotetext{
Mr Lowe presented a version of this paper at the 60th International Respiratory Congress of the American Association for Respiratory Care, held December 9-12, 2014, in Las Vegas, Nevada, and the 61st International Respiratory Congress of the American Association for Respiratory Care, held November 7-10, 2015, in Tampa, Florida.
}

The authors have disclosed no conflicts of interest.

Correspondence: Gary R Lowe MEd RRT-NPS RPFT, Respiratory Care, Slot 303, 1 Children's Way, Little Rock, AR 72202-3591. E-mail: lowegr@archildrens.org.

DOI: $10.4187 /$ respcare. 04857 
sessment, and alteration of therapy frequency based on the patient's respiratory status. It also provided the impetus for expansion of protocol-directed interventions into many facets of respiratory care. Since that time, numerous authors have added to this body of knowledge and

\section{See the Related Editorial on Page 380}

reported extensively on protocol use. Protocols have been reported to decrease unnecessary or harmful therapy, healthcare costs, and hospital length of stay while improving resource utilization, effectiveness and appropriateness of care, consistency of care, and patient outcomes, thereby improving the overall quality of patient care. ${ }^{2-8}$ Protocols involving numerous interventions, including oxygen titration, therapeutic interventions, and ventilator weaning, have been described and reported in the literature. ${ }^{9-13}$ These studies range from retrospective reviews to randomized controlled trials.

The Respiratory Care Department at Arkansas Children's Hospital has extensively utilized protocols in the medical and surgical units since 1994; however, they were not considered for implementation in the ICUs. The primary barrier was resistance from the medical staff and the prevailing attitude that, as a teaching institution, it was important that fellows and residents were given the opportunity to learn how to administer appropriate respiratory care orders and interventions. Ultimately, with the support of the Respiratory Care Services Medical Director and Critical Care Medicine Director, a plan was formulated to initiate a respiratory care protocol in the pediatric ICU (PICU) at the Arkansas Children's Hospital. This paper reviews the implementation and initial outcomes of a respiratory therapist (RT)-driven $\beta$-agonist/airway clearance protocol in the PICU.

\section{Methods}

This project was reviewed by the University of Arkansas for Medical Sciences institutional review board, which determined it was not human subject research. This study was composed of 2 parts: a survey administered to RTs and licensed independent practitioners and a retrospective review of outcome data comparing a therapist-driven $\beta$-agonist/airway clearance protocol with physician-directed respiratory care ordering. The $\beta$-agonist/airway clearance protocol was implemented in August 2013.

In the initial phase of this project, 2 survey tools were developed and administered via SurveyMonkey. One was e-mailed to RTs, consisted of 23 statements, and was sent to 46 potential responders. The other was e-mailed to licensed independent practitioners, which included physicians, fellows, and advanced practice nurses; consisted of 17 statements; and was sent to 25 potential responders. Respondents were assured that responses were confiden-

\section{QUICK LOOK}

\section{Current knowledge}

Respiratory therapist-driven protocols have become a standard of care in many health-care institutions throughout the country. Evidence has shown that therapistdriven protocols provide for effective and efficient allocation of respiratory care interventions. Therapistdriven protocols have been shown to improve the overall quality of patient care when properly implemented.

\section{What this paper contributes to our knowledge}

This paper summarizes the implementation of a therapistdriven protocol in a pediatric ICU. Survey tools were used to quantify the perceptions of health-care personnel regarding the initiation of the protocol. Outcome data were analyzed and revealed reductions in respiratory care interventions, ventilator days, and length of stay after the implementation of the protocol in this pediatric population.

tial and implied consent by participation and completion of the survey. The investigators were blinded to individual responses. The initial e-mail notification occurred 6 weeks after $\beta$-agonist/airway clearance protocol implementation. Two subsequent e-mail notifications occurred at 2 and 4 weeks after the initial notification. The surveys differed for RTs and licensed independent practitioners but contained 12 identical statements (Table 1). A 4-point Likert scale was used to quantify the responses and included the following options: totally disagree, somewhat disagree, somewhat agree, and totally agree. The 4-point Likert scale was used to eliminate neutral responses and encouraged respondents to either positively or negatively evaluate their perceptions of the survey statements. Results were aggregated into 2 groups, totally agree and somewhat agree versus totally disagree and somewhat disagree, and presented as percentages.

In the secondary phase, this study utilized a retrospective pre/post-intervention design. The target population included pediatric subjects admitted to the PICU with acute respiratory failure (ICD-9 codes 518.81, 518.51, 518.84, and 518.53). The $\beta$-agonist/airway clearance protocol was composed of a detailed clinical assessment resulting in a score (Table 2). The resulting score was used to initiate therapy frequency (Table 3). A higher score resulted in more frequent interventions. Subjects were reevaluated every $24 \mathrm{~h}$. Based on the reevaluation score obtained, the subject's frequency of therapy increased, decreased, or stayed the same based on objective data obtained during the clinical assessment. This process continued for the duration of the subject's PICU stay or until therapy was discontinued (Fig. 1).

Data were collected for one 6-month time period from October 2012 to March 2013 (Group 1; $n=152$ ) and 
Table 1. Statements Common to Both Survey Tools Administered to Respiratory Therapists and Licensed Independent Practitioners

1. I think that a reassessment of patients at $24 \mathrm{~h}$ is an appropriate time frame.

2. I feel that the implementation of the $\beta$-agonist/airway clearance protocol has elevated the status of the respiratory care staff.

3. I think that respiratory care has increased its value with the implementation of the $\beta$-agonist/airway clearance protocol.

4. I think the licensed independent practitioners (MDs and APNs) have accepted the $\beta$-agonist/airway clearance protocol.

5. I have noticed the licensed independent practitioners (MDs and APNs) discontinuing the $\beta$-agonist/airway clearance protocol.

6. I think the assessment score results in undertreating the patient.

7. I think the assessment score results in overtreating the patient.

8. I think the assessment score adequately treats the patient.

9. The $\beta$-agonist/airway clearance protocol provides consistency of care based on an objective scoring system.

10. The $\beta$-agonist/airway clearance protocol allows more effective care for patients.

11. Overall, the $\beta$-agonist/airway clearance protocol is an efficient system.

12. The implementation of the $\beta$-agonist/airway clearance protocol provides greater consistency of care for patients, especially when new licensed independent practitioners (MDs and APNs) come on service.

$\mathrm{MD}=$ physician

$\mathrm{APN}=$ advanced practice nurse

represented physician-directed respiratory care orders. These data were compared with one 6-month time period from October 2013 to March 2014 (Group 2; $n=171)$ and represented the therapist-driven $\beta$ agonist/airway clearance protocol. Data were included only if the entire PICU stay was inclusive of each specific time period. Data elements included subject age (months), PICU length of stay (d), daily acuity (based on a single assigned value each day), weighted daily acuity (based on the actual number of nursing care hours each day), number of $\beta$-agonist interventions (aerosol and metered-dose inhaler), number of airway clearance interventions (chest physiotherapy and intrapulmonary percussive ventilation), $d$ receiving mechanical ventilation, pediatric index of mortality 2, pediatric index of mortality 2 rate of mortality, pediatric risk of mortality 3 , and pediatric risk of mortality 3 probability of death scores.

\section{Statistical Analysis}

Descriptive statistics of subject characteristics were summarized and compared between the pre-intervention (Group 1) and post-intervention (Group 2) groups. For continuous variables, mean and SD as well as median and range are presented. For categorical variables, count and percentage are presented. Continuous variables were tested for normality using the Shapiro-Wilk test. If nonnormality is detected, comparison of continuous variables was performed using Mann-Whitney tests. Comparison of categorical variables was performed using chi-square tests.

In investigating the effect of the $\beta$-agonist/airway clearance protocol implementation on various subject outcomes, Poisson regression was used because all 4 outcome variables were right-skewed. Subject characteristics were included in the multivariable Poisson regression model as covariates and were assessed for collinearity. Collinearity was defined as a value $>2$ after taking the square root of the variance. Coefficient estimates of intervention, 95\% CIs, and $P$ values are presented for each of the outcome variables. All analyses were performed in SAS 9.4 (SAS Institute, Cary, North Carolina). $P$ values of $<.05$ were considered statistically significant.

\section{Results}

For the survey, the response rate was $37 \%$ (17/46) for RT and $28 \%$ (7/25) for licensed independent practitioners, which resulted in an overall response rate of $34 \%$ for both groups (Table 4). For the 17 RT respondents, $59 \%$ were male, $47 \%$ were between the ages of 25 and $40 \mathrm{y}, 53 \%$ were $\geq 40 \mathrm{y}$ old, and $71 \%$ had $<20 \mathrm{y}$ of experience. For the 7 licensed independent practitioner respondents, $29 \%$ were male, $86 \%$ were between the ages of 25 and 40 years, $14 \%$ were $\geq 40$ y old, and all had $<20$ y of experience.

Survey results are shown in Table 5. Staff who completed the survey responded that they felt that subject reassessment at $24 \mathrm{~h}$ was an appropriate time frame (RTs, $88 \%$; licensed independent practitioners, $72 \%$ ). Both groups reportedly perceived that implementation of the $\beta$-agonist/airway clearance protocol had elevated the status of the respiratory care staff (RTs, 71\%; licensed independent practitioners, $71 \%$ ) and that the respiratory care staff had increased their value (RTs, 77\%; licensed independent practitioners, 71\%). They claimed that the licensed independent practitioners had accepted the $\beta$-agonist/airway clearance protocol as a part of the PICU standard of care (RTs, 59\%; licensed independent practitioners, $86 \%$ ). Responses diverged concerning the statement that licensed independent practitioners discontinued the $\beta$-agonist/airway clearance protocol, which revealed that $41 \%$ of RTs agreed that this was true versus $57 \%$ of licensed independent practitioners. Feedback also differed concerning the statement that the assessment score resulted in overtreating the patient (RTs, 29\%; licensed independent practitioners, $0 \%$ ). Most responders stated that they considered the assessment score to be adequately determining treatment of the patient (RTs, 77\%; licensed indepen- 


\section{RT-Driven $\beta$-Agonist/Airway Clearance Protocol in the PICU}

Table 2. Scoring Tool Used With the $\beta$-Agonist/Airway Clearance Protocol

\begin{tabular}{|c|c|c|c|}
\hline Item & Score $=0$ & Score $=1$ & Score $=2$ \\
\hline History & $\begin{array}{l}\text { No underlying pulmonary } \\
\text { diagnosis }\end{array}$ & $\begin{array}{l}\text { History of underlying pulmonary } \\
\text { disease or premature newborn }\end{array}$ & $\begin{array}{l}\text { History of underlying pulmonary disease } \\
\text { with exacerbation; or receiving } \\
\text { mechanical ventilation or bi-level } \\
\text { ventilation }\end{array}$ \\
\hline Gestalt & Alert, responsive & $\begin{array}{l}\text { Anxious or fearful; or altered level of } \\
\text { consciousness or lethargic }\end{array}$ & $\begin{array}{l}\text { Obtunded or non-responsive; or receiving } \\
\text { mechanical ventilation }\end{array}$ \\
\hline Cough & None & $\begin{array}{l}\text { Present but effective for clearing } \\
\text { secretions }\end{array}$ & $\begin{array}{l}\text { Ineffective in clearing secretions, non- } \\
\text { existent, persistent, or constant }\end{array}$ \\
\hline Surgery (past 14 d) & $\begin{array}{l}\text { None; or other than specified } \\
\text { for score } 1 \text { or score } 2\end{array}$ & $\begin{array}{l}\text { Major spinal surgery, lower extremity } \\
\text { surgery; or neurosurgery }\end{array}$ & $\begin{array}{l}\text { Thoracic or upper abdominal surgery; or } \\
\text { surgery and history of underlying } \\
\text { pulmonary disease }\end{array}$ \\
\hline $\begin{array}{c}\text { Breathing pattern/work of } \\
\text { breathing/activity level }\end{array}$ & $\begin{array}{l}\text { Ribcage/abdominal synchrony } \\
\text { or baseline; no retractions; } \\
\text { no dyspnea with normal } \\
\text { speech; ambulatory or } \\
\text { normal activity for age }\end{array}$ & $\begin{array}{l}\text { Moderate dyspnea with 5-8-word } \\
\text { sentences; or decreased activity or } \\
\text { out of bed with assistance. Mild } \\
\text { increase in work of breathing, } \\
\text { flaring, retracting, tracheal tug }\end{array}$ & $\begin{array}{l}\text { Ribcage/abdominal asynchrony; moderate } \\
\text { to severe work of breathing or dyspnea } \\
\text { with }<5 \text {-word sentences; or } \\
\text { concentrates on breathing; immobile } \\
\text { and predominantly in supine position; } \\
\text { intercostal, suprasternal, or subcostal } \\
\text { retractions; sternocleidomastoid muscle } \\
\text { or head bobbing; nasal flaring; } \\
\text { grunting; intercostal, suprasternal, or } \\
\text { subcostal retractions }\end{array}$ \\
\hline Breathing frequency & Normal for age & $\begin{array}{l}\text { Frequency }>10 \text { breaths/min above } \\
\text { normal parameters }\end{array}$ & $\begin{array}{l}\text { Frequency }>20 \text { breaths/min above } \\
\text { normal parameters }\end{array}$ \\
\hline Secretions & Normal oral secretions & $\begin{array}{l}\text { Significant volume of clear or white } \\
\text { secretions }\end{array}$ & $\begin{array}{l}\text { Significant volume of yellow or green } \\
\text { secretions }\end{array}$ \\
\hline Breath sounds & $\begin{array}{l}\text { Clear and equal with good } \\
\text { aeration, upper airway } \\
\text { congestion only or baseline }\end{array}$ & $\begin{array}{l}\text { End expiratory wheezes; or fine end- } \\
\text { inspiratory crackles; or crackles in } \\
\text { one segment only }\end{array}$ & $\begin{array}{l}\text { Wheezing throughout expiration; or } \\
\text { inspiratory/expiratory wheezing; or } \\
\text { early, mid, or continuous inspiratory or } \\
\text { expiratory crackles; or crackles in } \\
\text { more than one segment; or diminished }\end{array}$ \\
\hline Prolonged expiration & None & & Moderate-severe \\
\hline Pulse oximetry & $\begin{array}{l}>95 \% \text { receiving room air; or } \\
\text { pulse oximetry not } \\
\text { indicated }\end{array}$ & $\begin{array}{l}\text { 92-94\% receiving room air (does not } \\
\text { apply to congenital heart disease } \\
\text { patients) }\end{array}$ & $\begin{array}{l}<92 \% \text { receiving room air; or patient } \\
\text { receiving oxygen (does not apply to } \\
\text { congenital heart disease patients }\end{array}$ \\
\hline Sputum culture (past $14 \mathrm{~d}$ ) & None; normal flora & & Abnormal bacteria or fungus \\
\hline Chest radiograph & $\begin{array}{l}\text { None; or no evidence of } \\
\text { hyperexpansion, focal } \\
\text { infiltrate, or atelectasis }\end{array}$ & & $\begin{array}{l}\text { Hyperexpansion, focal infiltrate, or } \\
\text { segmental or lobar atelectasis }\end{array}$ \\
\hline
\end{tabular}

Table 3. Therapy Frequency Based on $\beta$-Agonist/Airway Clearance Protocol Score

\begin{tabular}{lcc}
\hline \hline RCS & $\begin{array}{c}\text { Therapy } \\
\text { Frequency }\end{array}$ & $\begin{array}{c}\text { RCS } \\
\text { Reevaluation }\end{array}$ \\
\hline $0-3$ & $\begin{array}{c}\text { Discontinue, as needed, } \\
\text { or home regimen }\end{array}$ & $\begin{array}{c}\text { All reevaluations every } \\
24 \text { h on day shift }\end{array}$ \\
$4-6$ & $12 \mathrm{~h}$ & \\
$7-9$ & $8 \mathrm{~h}$ \\
$10-12$ & $6 \mathrm{~h}$ \\
$>13$ & $4 \mathrm{~h}$ \\
& \\
RCS = respiratory care score & \\
\hline
\end{tabular}

dent practitioners, $71 \%$ ) and that the $\beta$-agonist/airway clearance protocol provided consistency of care based on an objective scoring system (RTs, 76\%; licensed independent

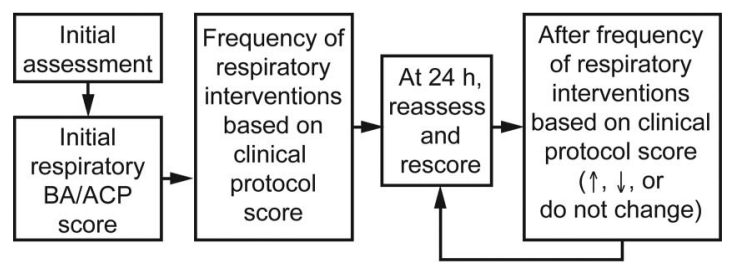

Fig. 1. Intervention flow diagram for the $\beta$-agonist/airway clearance protocol (BA/ACP).

practitioners, $71 \%$ ). Both groups answered that the $\beta$ agonist/airway clearance protocol allowed for more effective care of patients (RTs, 88\%; licensed independent practitioners, $71 \%$ ) and that it was an efficient system (RTs, $71 \%$; licensed independent practitioners, $71 \%$ ). According to the survey, they also regarded the implementation of the $\beta$ agonist/airway clearance protocol as providing greater con- 
sistency of care for patients when a new licensed independent practitioner came on service (RTs, 100\%; licensed independent practitioners, $57 \%$ ).

In the second phase of the project, comparisons for mean age, mean stay, mean daily acuity, mean weighted daily acuity, $\beta$-agonist interventions, airway clearance interventions, ventilator days, mean pediatric index of mortality 2 scores, mean pediatric index of mortality 2 rate of mortality scores, mean pediatric risk of mortality 3 scores, and mean pediatric risk of mortality 3 probability of death scores were analyzed (Table 6). For the comparison of Group 1 (pre-intervention, physician-directed orders, $n=152$ ) with Group 2 (post-intervention, therapist-driven protocols, $n=171$ ), there were no significant differences in mean age (78.1 months vs 60.7 months, $P=.33$ ) or sex

Table 4. Demographic Characteristics of Respiratory Therapist and Licensed Independent Practitioner Survey Responders

\begin{tabular}{llr}
\hline \hline \multicolumn{1}{c}{ Characteristics } & RT & LIP \\
\hline Response rate & $37 *$ & $28 *$ \\
Male & $59 \dagger$ & $29 \dagger$ \\
Age $25-40$ y & $47 \dagger$ & $86 \dagger$ \\
Age $>40$ y & $53 \dagger$ & $14 \dagger$ \\
Experience $<20$ y & $71 \dagger$ & $100 \dagger$ \\
& & \\
Results are shown as percentages. & \\
$*$ Percentage calculation based on 46 potential respiratory therapist responders and 25 & \\
potential licensed independent provider responders. & \\
$\dagger$ Percentage calculation based on 17 respiratory therapist responders and 7 licensed \\
independent provider responders. & \\
RT $=$ respiratory therapist & \\
LIP $=$ licensed independent practitioner & \\
&
\end{tabular}

(43.5\% males vs $51.4 \%, P=.19$ ). There were also no significant differences for mean daily acuity (3.3 vs 3.3, $P>.99$ ) or mean weighted daily acuity (3.9 vs $3.8, P=.79$ ). There were no differences in means for pediatric index of mortality 2, pediatric index of mortality 2 rate of mortality, pediatric risk of mortality 3 probability of death, and pediatric risk of mortality 3 scores $(P=.63, .56, .19$, and .44 , respectively).

Without controlling for any subject characteristics, raw comparison of outcomes showed that all were improved in Group 2 (post-intervention), with decreased length of stay (d), fewer $\beta$-agonist therapies, fewer airway clearance therapies, and fewer days on a ventilator (Fig. 2). The effects of the intervention on various subject outcomes (length of stay, $\beta$-agonist therapies, airway clearance therapies, and ventilator days) were adjusted for subject characteristics in the Poisson regression model (Table 7). When comparing subjects with the same age, sex, weighted average daily acuity, pediatric index of mortality 2 rate of mortality, and pediatric risk of mortality 3 probability of death scores, the stay for Group 2 (post-intervention) was observed to be 0.845 d (95\% CI $0.780-0.915)$ compared with every $1 \mathrm{~d}$ of stay for Group 1 (pre-intervention). This comparison represented a reduction of length of stay in the post-intervention group by $15.5 \%$ (calculated as $[1-0.845] / 1$ ). Similarly, when adjusted for age, sex, weighted average daily acuity, pediatric index of mortality 2 rate of mortality, and pediatric risk of mortality 3 probability of death score, $\beta$-agonist interventions were observed to be 0.63 times less frequent (95\% CI 0.598-0.664) for Group 2; the airway clearance interventions were noted to be 0.782

Table 5. Survey Responses of Respiratory Therapists and Licensed Independent Practitioners Who Totally or Somewhat Agreed With Each Statement

\begin{tabular}{|c|c|c|}
\hline Survey Statement & $\mathrm{RT}(n=17)$ & LIP $(n=7)$ \\
\hline Reassessment of patients at $24 \mathrm{~h}$ is an appropriate time frame. & 88 & 72 \\
\hline Implementation of the BA/ACP has elevated the status of the respiratory care staff. & 71 & 71 \\
\hline Respiratory care has increased its value with the implementation of the BA/ACP. & 77 & 71 \\
\hline LIPs (MDs and APNs) have accepted the BA/ACP. & 59 & 86 \\
\hline I have noticed the LIPs (MDs and APNs) discontinuing the BA/ACP. & 41 & 57 \\
\hline The assessment score results in undertreating the patient. & 6 & 57 \\
\hline The assessment score results in overtreating the patient. & 29 & 0 \\
\hline The assessment score adequately treats the patient. & 77 & 71 \\
\hline The BA/ACP provides consistency of care based on an objective scoring system. & 76 & 71 \\
\hline The BA/ACP allows more effective care for patients. & 88 & 71 \\
\hline The BA/ACP is an efficient system. & 71 & 71 \\
\hline $\begin{array}{l}\text { The implementation of the BA/ACP provides greater consistency of care for patients, especially } \\
\text { when new LIPs (MDs and APNs) come on service. }\end{array}$ & 100 & 57 \\
\hline $\begin{array}{l}\text { Results are shown as percentages } \\
\text { RT }=\text { respiratory therapist } \\
\text { LIP = licensed independent practitioner } \\
\mathrm{MD}=\text { physician } \\
\mathrm{APN}=\text { advanced practice nurse } \\
\mathrm{BA} / \mathrm{ACP}=\beta \text {-agonist/airway clearance protocol }\end{array}$ & & \\
\hline
\end{tabular}


RT-Driven $\beta$-Agonist/Airway Clearance Protocol in the PICU

Table 6. Summary Statistics of All Variables Pre- and Post-Intervention

\begin{tabular}{|c|c|c|c|}
\hline Subject Characteristics & Pre-Intervention Group $1(n=152)$ & Post-Intervention Group $2(n=171)$ & $P$ \\
\hline Age, months & & & .33 \\
\hline Mean $\pm \mathrm{SD}$ & $78.1 \pm 89.7$ & $60.7 \pm 68.6$ & \\
\hline Median (range) & $26.0(0.5-424.0)$ & $28.0(0.0-297.0)$ & \\
\hline Sex, $n(\%)$ & & & .19 \\
\hline Male & $77(43.5)$ & $100(51.4)$ & \\
\hline Female & $75(56.5)$ & $71(48.6)$ & \\
\hline Average daily acuity & & & $>.99$ \\
\hline Mean \pm SD & $3.3 \pm 0.5$ & $3.3 \pm 0.4$ & \\
\hline Median (range) & $3.2(2.3-5.0)$ & $3.2(2.5-4.6)$ & \\
\hline Weighted average daily acuity & & & .79 \\
\hline Mean \pm SD & $3.9 \pm 1.3$ & $3.8 \pm 1.1$ & \\
\hline Median (range) & $3.5(1.7-10.0)$ & $3.6(2.0-8.5)$ & \\
\hline PIM2 score & & & .63 \\
\hline Mean \pm SD & $-3.7 \pm 1.8$ & $-3.9 \pm 1.3$ & \\
\hline Median (range) & $-3.5(-6.5$ to 4.5$)$ & $-3.5(-6.5$ to 1.53$)$ & \\
\hline PIM2 ROM & & & .56 \\
\hline Mean \pm SD & $7.8 \pm 19.0$ & $4.4 \pm 10.0$ & \\
\hline Median (range) & $3.0(0.2-98.9)$ & $3.0(0.2-82.3)$ & \\
\hline PRISM3 probability of death & & & .19 \\
\hline Mean \pm SD & $7.1 \pm 20.0$ & $5.3 \pm 16.0$ & \\
\hline Median (range) & $0.8(0.1-97.3)$ & $0.8(0.1-98.6)$ & \\
\hline PRISM3 score & & & .44 \\
\hline Mean \pm SD & $6.4 \pm 8.0$ & $5.5 \pm 7.1$ & \\
\hline Median (range) & $4.0(0.0-42.0)$ & $3.0(0.0-41.0)$ & \\
\hline \multicolumn{4}{|c|}{$\begin{array}{l}P \text { was estimated using } 2 \text {-sample independent Mann-Whitney tests for continuous variables and chi-square tests for categorical variables. } \\
\text { PIM2 = pediatric index of mortality } 2 \\
\text { ROM = rate of mortality } \\
\text { PRISM3 = pediatric risk of mortality } 3\end{array}$} \\
\hline
\end{tabular}

times less frequent (95\% CI 0.753-0.812) for Group 2; and the number of ventilator days for Group 2 was noted to be $0.748 \mathrm{~d}$ (95\% CI $0.685-0.819)$ compared with every 1 ventilator day for Group 1. These comparisons represented a reduction of $37 \%$ in the number of $\beta$-agonist interventions, $21.8 \%$ in the number of airway clearance interventions, and $25.2 \%$ in total ventilator days. Overall, comparing Group 1 (pre-implementation) with Group 2 (post-implementation), all outcome measures (length of stay, $\beta$-agonist therapies, airway clearance therapies, and ventilator days) showed statistically significant reductions adjusting for subject characteristics $(P<.001)$.

\section{Discussion}

Changes in standard accepted practice are frequently met with resistance. This has been addressed by Tietsort et $\mathrm{al}^{2}$ and Stoller et al. ${ }^{14}$ As they noted, if initiation of protocols were introduced and marketed correctly, then resistance could be minimized during implementation and subsequent continuation of the program. Following guidelines similar to those that they outlined, the initiation of this project occurred with key stakeholders and included physicians, advanced practice nurses, and a core group of respiratory care personnel who worked primarily in the PICU. These groups met and discussed the possibility of introducing the $\beta$-agonist/airway clearance protocol in the PICU. The initial template was developed based on an existing protocol that was used on the medical and surgical units and was revised and enhanced to encompass the critical nature of the patients who would be treated in the PICU. After several meetings, the proposed protocol was communicated to all personnel who frequently worked in the PICU. Suggested changes were incorporated into the protocol and then re-sent for further comment and revision. Acceptance of the protocol was increased by active marketing and face-to-face discussions with all affected personnel. Additionally, the PICU respiratory care core personnel were involved in the development of the plan that was eventually adopted, and this extensive interdepartmental collaboration and cooperation may have led to an improved sense of ownership and acceptance of the protocol despite anticipated resistance to changes of this magnitude.

Acceptance of the protocol was evident in the survey responses, since overall perceptions surrounding the im- 

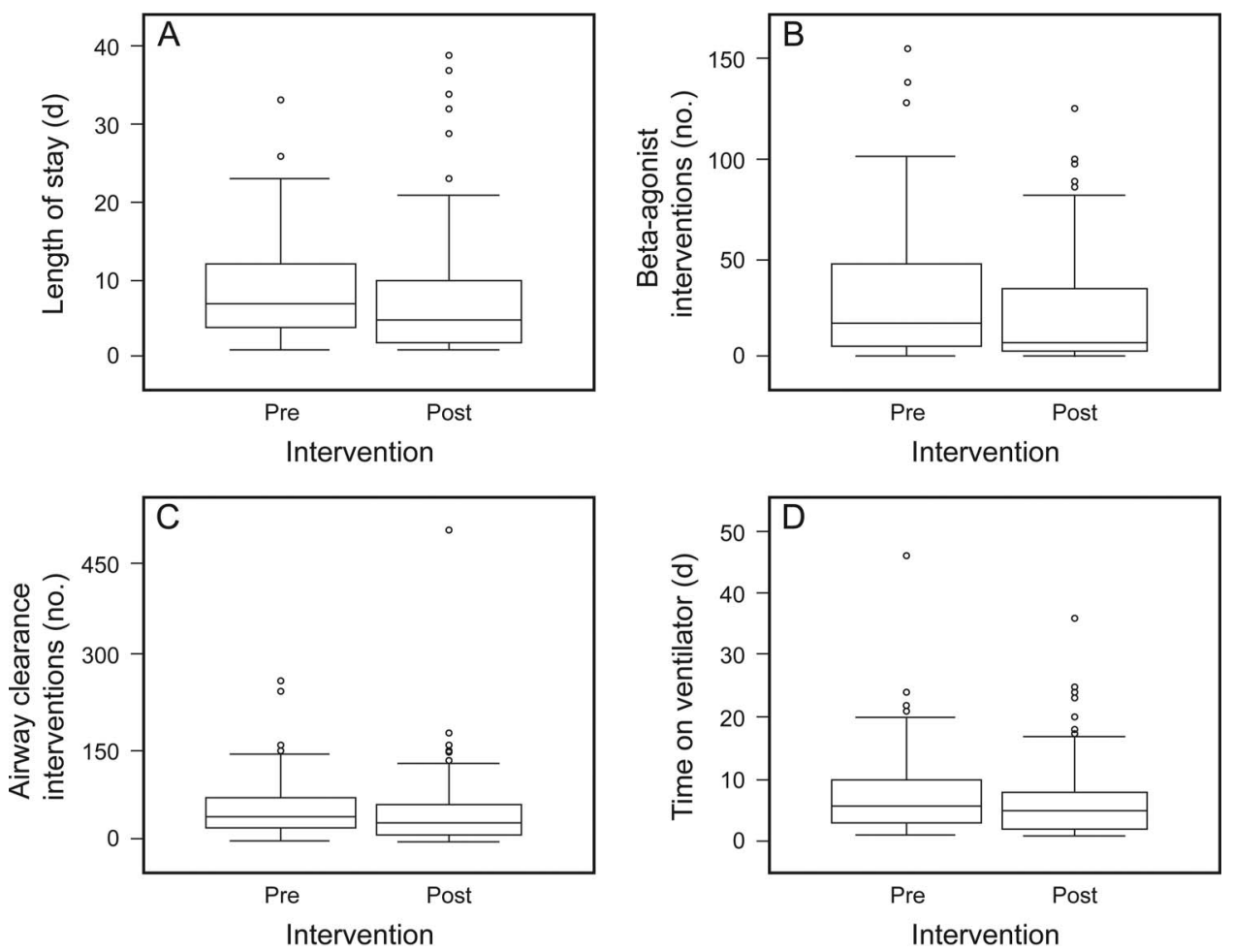

Fig. 2. Comparison of subject outcomes between pre- and post-intervention groups. Boxes show 25th and 75th percentiles, and center lines denote the median. Whiskers represent upper and lower adjacent values, defined as the largest observation that is $\leq 75$ th percentile +1.5 interquartile ranges and the smallest observation that is $\geq 25$ th percentile -1.5 interquartile ranges. Points denote outliers.

Table 7. Effect of the $\beta$-Agonist/Airway Clearance Protocol Implementation on Various Subject Outcomes

\begin{tabular}{|c|c|c|c|c|}
\hline Subject Outcome & Coefficient Estimate & $95 \% \mathrm{CI}$ & $P$ & $\begin{array}{l}\text { Percentage Reduction in } \\
\text { Group } 2 \text { vs Group } 1\end{array}$ \\
\hline \multicolumn{5}{|l|}{ LOS } \\
\hline Before (Group 1) & Reference & & & \\
\hline After (Group 2) & 0.845 & $0.780-0.915$ & $<.001$ & 15.5 \\
\hline \multicolumn{5}{|l|}{$\beta$-Agonist therapies } \\
\hline Before (Group 1) & Reference & & & \\
\hline After (Group 2) & 0.630 & $0.598-0.664$ & $<.001$ & 37 \\
\hline \multicolumn{5}{|c|}{ Airway clearance therapies } \\
\hline Before (Group 1) & Reference & & & \\
\hline After (Group 2) & 0.782 & $0.753-0.812$ & $<.001$ & 21.8 \\
\hline \multicolumn{5}{|l|}{ Ventilator days } \\
\hline Before (Group 1) & Reference & & & \\
\hline After (Group 2) & 0.748 & $0.685-0.819$ & $<.001$ & 25.2 \\
\hline
\end{tabular}

plementation of the $\beta$-agonist/airway clearance protocol were positive. Of particular interest in the survey responses was that both groups perceived that the implementation of the $\beta$-agonist/airway clearance protocol elevated the status and increased the value of the RTs. This reinforces previous research on these phenomena. As Metcalf et $\mathrm{al}^{6}$ report, greater use of protocols increases RT job satisfaction. Al- though the survey did not directly ask about job satisfaction, it can be surmised that increasing the status and value of RTs could lead to enhanced job satisfaction. The survey responses helped to validate previous research in that this protocol allowed for adequate treatment of the patient, provided greater consistency of patient care based on an objective scoring system, and was an effective and effi- 
cient system for therapeutic interventions. The protocol also allowed for a smoother transition of care when a new licensed independent practitioner came on service, allocating appropriate care to patients based on objective criteria rather than changing the therapy regimen in the absence of a change in patient status due to personal biases of the licensed independent practitioners.

In evaluating any new program, like the initiation of $\beta$-agonist/airway clearance protocol protocol, staff feedback is of extreme importance to monitor successful acceptance. This project utilized e-mail notification with an embedded link to an online survey tool, and the combined survey response rate for RTs and licensed independent practitioners of $34 \%$ appears to be consistent with the expected response rate for online-based internal surveys. For example, Sheehan ${ }^{15}$ found, after reviewing 31 studies, that the average response rate for e-mail surveys was $36.8 \%$. Also, according to SurveyGizmo, internal surveys will generally receive a $30-40 \%$ response rate. ${ }^{16}$ Nulty $^{17}$ compared paper-based survey responses versus online survey responses and found a $33 \%$ overall response rate to online surveys. The surveys provided valuable information on the appropriateness of assessment times and frequency of interventions in treating the patient.

The implementation of the $\beta$-agonist/airway clearance protocol also positively impacted outcomes in subjects admitted with acute respiratory failure. The rationale for selecting this subgroup of PICU patients was that they were thought to be the most likely to require respiratory care interventions. Additionally, this research adds evidence to the body of knowledge in a population where current information is lacking. Modrykamien and Stoller ${ }^{3}$ and Stoller ${ }^{18}$ pointed out that additional study to assess the efficacy of protocols needed to be carried out in settings like the PICU. This analysis helps to address that observation. This study indicates that subject characteristics in both pre-intervention and post-intervention groups were similar. There were overall reductions in the number of $\beta$-agonist interventions, number of airway clearance interventions, and ventilator days in the post-intervention group. Additionally, all outcome measures (length of stay, $\beta$-agonist therapies, airway clearance therapies, and ventilator days) showed statistically significant reductions, adjusting for subject characteristics in the post-intervention group. These results are considered by the authors as also being clinically important, with a reduction of at least $15 \%$ in these parameters. Although not specifically measured in this study, decreased stay in the ICU and a decrease in ventilator days were associated with significant cost savings and resulted in more efficient use of the RT's time when unnecessary treatments were eliminated.

This study has several limitations. First, this study was retrospective in design, and there was no ability to control for potential confounding variables; however, every effort was made to compare similar populations pre- and postintervention. In addition, at the time of the study, there were no changes in either technology or clinical practice approach to explain these findings. Second, the outcomes noted in this study reflect the realities of Arkansas Children's Hospital and may not be generalizable to other institutions. Finally, although the pre- and post-intervention groups were similar, factors that could not be accounted for may have influenced the reported findings.

\section{Conclusion}

This study adds to the growing number of publications addressing RT-driven protocols. It also fills a niche in the knowledge base where clinical data are scant; specifically, the PICU. Implementation of a $\beta$-agonist/airway clearance protocol was perceived as a positive development by RTs and licensed independent practitioners based on the survey responses. The implementation of the $\beta$-agonist/airway clearance protocol resulted in significant reductions of patient interventions and improved outcomes by decreasing ICU stay and ventilator days.

\section{ACKNOWLEDGMENTS}

We thank the RTs and licensed independent practitioners from the PICU at Arkansas Children's Hospital for input and support for this project.

\section{REFERENCES}

1. Nielsen-Tietsort J, Poole B, Creagh CE, Repsher LE. Respiratory care protocol: an approach to in-hospital respiratory therapy. Respir Care 1981;26(5):430-436.

2. Tietsort J, McPeck M, Rinaldo-Gallo S. Respiratory care protocol development and impact. Respir Care Clin N Am 2004;10(2):223234.

3. Modrykamien AM, Stoller JK. The scientific basis for protocoldirected respiratory care. Respir Care 2013;58(10):1662-1668.

4. Kallam A, Meyerink K, Modrykamien AM. Physician-ordered aerosol therapy versus respiratory therapist-driven aerosol protocol: the effect on resource utilization. Respir Care 2013;58(3):431-437.

5. Maselli DJ, Fernandez JF. Can respiratory therapist-driven protocols improve resource utilization? Respir Care 2013;58(3):546-547.

6. Metcalf AY, Stoller JK, Fry TD, Habermann M. Patterns and factors associated with respiratory care protocol use. Respir Care 2015; 60(5):636-643.

7. Stewart KJ. Managing respiratory care: where is the science? Respir Care 2008;53(7):903-907.

8. Werre ND, Boucher EL, Beachey WD. Comparison of therapistdriven and physician-directed respiratory care in COPD subjects with acute pneumonia. Respir Care 2015;60(2):151-154.

9. Komara JJ Jr, Stoller JK. The impact of a postoperative oxygen therapy protocol on use of pulse oximetry and oxygen therapy. Respir Care 1995;40(11):1125-1129.

10. Shapiro BA, Cane RD, Peterson J, Weber D. Authoritative medical direction can assure cost-beneficial bronchial hygiene therapy. Chest 1988;93(5):1038-1042. 
11. Alexander E, Weingarten S, Mohsenifar Z. Clinical strategies to reduce utilization of chest physiotherapy without compromising patient care. Chest 1996;110(2):430-432.

12. Marelich GP, Murin S, Battistella F, Inciardi J, Vierra T, Roby M. Protocol weaning of mechanical ventilation in medical and surgical patients by respiratory care practitioners and nurses: effect on weaning time and incidence of ventilator-associated pneumonia. Chest 2000;118(2):459-467.

13. Kollef MH, Shapiro SD, Silver P, St John RE, Prentice D, Sauer S, et al. A randomized, controlled trial of protocol-directed versus physician-directed weaning from mechanical ventilation. Crit Care Med 1997;25(4):567-574.
14. Stoller JK. Implementing change in respiratory care. Respir Care 2010;55(6):749-757.

15. Sheehan KB. E-mail survey response rates: a review. J Comput Mediat Commun 2001;6(2):0. doi: 10.1111/j.1083-6101.2001. tb00117.x.

16. Fryrear A. Survey response rates. SurveyGizmo: Jul 27, 2015. http:// www.surveygizmo.com/survey-blog/survey-response-rates. Accessed March 23, 2016.

17. Nulty DD. The adequacy of response rates to online and paper surveys: what can be done? Assess Eval Higher Educ 2008;33(3):301-314.

18. Stoller JK. The effectiveness of respiratory care protocols. Respir Care 2004;49(7):761-765.

This article is approved for Continuing Respiratory Care Education credit. For information and to obtain your CRCE

(free to AARC members) visit

www.rcjournal.com 